\title{
Bone Marrow-derived Mesenchymal Stem Cells Reverse Hepatic Fibrosis, Improved Vascularity, and Attenuate the Apoptosis in Carbon Tetrachloride-induced Hepatic Fibrosis Experimental Rats
}

\author{
${\text { Zainab } \text { Altaib }^{1} \text { (D) W. S. Sabbah }}^{2}$ (D) Eman K. Rashwan ${ }^{3,4}$ D, Ashraf Albrakati $^{5} \mathbb{D}$, Abeer Mostafa $^{6 *}$ (iD \\ ${ }^{1}$ Department of Histology and Cell Biology, Faculty of Medicine, Helwan University, Helwan, Egypt; ${ }^{2}$ Department of Anatomy, \\ Faculty of Medicine for Girls, Al Azhar University, Cairo, Egypt; ${ }^{3}$ Department of Physiology, College of Medicine, Jouf University, \\ Sakaka, Saudi Arabia; ${ }^{4}$ Department of Physiology, College of Medicine, Al-Azhar University, Assuit, Egypt; ${ }^{5}$ Department of \\ Human Anatomy, College of Medicine, Taif University, Taif, Saudi Arabia; ${ }^{6}$ Department of Medical Biochemistry and Molecular \\ Biology, Faculty of Medicine, Cairo University, Cairo, Egypt
}

dited by: Slavica Hristomanova-Mitkovska Citation: Altaib Z, Sabbah WS, Rashwan EK, Albraka A, Mostafa A. Bone Marrow-Derived Mesenchymal Stem Cells Reverse Hepatic Fibrosis, Improved Vascularity, and Attenuate the Apoptosis in Carbon Tetrachloride-Induced Hepatic Fibrosis Experiment Raced Med Sci. 2021 Aug 14, 9(A):698-706. yords: Mesenchymal stem cells; Liver fibrosis; flammatory cytokines and vascular endothelial growth

factor Medical Biochemistry and Molecular Biology, Faculty of Medicine, Cairo University, Cairo, Egypt. E-mail: dr_abeer. mostafa@yahoo.com Received: 06-Jun-2021 Revised: 25-Jun-2021 Accepted: 04-Aug-2021 Eman K. Rashwan, Ashraf Albrakati, Abeer Mostaf, ist: The authors have declared that $n$ competing interest exists
Open Access: This is an open-access article distributed under the terms of the Creative Commons AttributionNonCommercial 4.0 International License (CC BY-NC 4.0)

\section{Abstract}

BACKGROUND: Liver fibrosis is a sequel of different chronic inflammatory diseases. The most effective treatment for end-stage liver fibrosis is liver transplantation; but the shortage of donor organs, immunological rejection, surgical complications, and high medical costs limit the transplantation. That's why we are in argent need to develop new strategies in treatment.

AIM: The objectives of the study were to evaluate the role of mesenchymal stem cells (MSCs) in regenerating live cells and reverse hepatic fibrosis.

MATERIALS AND METHODS: Thirty animals were randomly divided into three groups (10 animals each): Group 1 A negative control; Group 2: Induced liver fibrosis (pathological control); and Group 3: Induced liver fibrosis that received undifferentiated BM MSCs $\left(3 \times 10^{6} \mathrm{cells} / \mathrm{ml}\right.$ intraperitoneally/single dose $)$; the extent of fibrosis vascularization, and inflammation and hepatic cell apoptosis were evaluated together with the assessment of liver functions.

RESULTS: The MSCs treated group showed significant improvement of liver functions, and attenuation of fibrosis histopathologically and downregulate the expression of transforming growth factor $B$ versus the induced fibrosis group. Inflammatory marker (tumor necrosis factor and IL-6) was downregulated and vascularity was restored in MSCs treated group compared to carbon tetrachloride-induced fibrosis rats.

CONCLUSION: MSCs provide promising therapeutic agents in the treatment of liver fibrosis.

\section{Background}

Liver fibrosis is one of the most common hepatic diseases, it could be result as a consequence of chronic inflammation such as steatohepatitis, hepatitis C virus infection, alcoholism, and drug toxicity. Like any inflammatory lesion, it heals by fibrous tissue formation with deposition of excessive extracellular matrix (ECM) around hepatocyte. Liver fibrosis may be complicated by portal hypertension, hepatocellular carcinoma, and liver cell failure [1].

It is essential to understanding the molecular mechanisms of hepatic fibrosis to develop new treatments. Although antifibrotic activity of many compounds has been studied experimentally, none has been validated in the clinic or commercialized as a therapy for fibrosis [2]. Thus, the development of new treatment strategies is necessary.
Mesenchymal stem cells (MSCs) are multipotent cells that are capable of migration to damaged tissues and regenerate them. Damaged tissues produce inflammatory cytokines that induce chemotaxis of MSCs [3]. MSCs have immune modulatory properties and the ability to differentiate into hepatocytes, MSCs also secrete trophic factors, such as growth factors and cytokines. Furthermore, MSCs can suppress inflammatory responses, increase hepatocyte regeneration, reduce hepatocyte apoptosis, inhibit liver fibrosis, and improve liver function [3].

ECM proteins deposition in hepatic fibrosis is mediated primarily by activated hepatic stellate cells (HSCs). Liver insult activates HSCs, $\alpha$-smooth muscle actin (SMA)-positive, and myofibroblastlike cells with increased collagen synthesis [4]. The antifibrotic role of MSCs could be mediated through inhibiting the proliferation of activated HSCs and collagen synthesis by indirect or direct cell-cell contact. Furthermore, MSCs secrete trophic factors as HGF, 
IL-10, transforming growth factor (TGF- $\beta 3$ ), and tumor necrosis factor (TNF- $\alpha$ ) that inhibit the proliferation of HSCs and decrease collagen synthesis. In addition, HGF can promote the apoptosis of HSCs [5]. It has been reported that MSCs when directly cocultured with HSCs significantly inhibit the proliferation and $\alpha-S M A$ expression of HSCs through cell-cell contact [6].

\section{Methods}

\section{Isolation and preparation of BM-derived MSC}

A 6-week-old white albino rats' tibiae and femurs were flushed with Dulbecco's Modified Eagle's Medium, GIBCO/BRL with added $10 \%$ fetal bovine serum (GIBCO/BRL) to harvest the bone marrow. Nucleated cells were isolated with a density gradient (Ficoll/Paque [Pharmacia]) and resuspended in complete culture medium with added $1 \%$ penicillin-streptomycin (GIBCO/ $\mathrm{BRL}$ ) for $10-14$ days; cells were incubated at $37^{\circ} \mathrm{C}$ in $5 \%$ humidified $\mathrm{CO}_{2}$ until reach (80-90\% confluence), after that, cultured cells were washed and then trypsinized with $0.25 \%$ trypsin in $1 \mathrm{mM}$ EDTA (GIBCO/BRL). The harvested cells were centrifuged (at $2400 \mathrm{rpm}$ for $20 \mathrm{~min}$ ), then resuspended with serum-supplemented medium and incubated in $50 \mathrm{~cm}^{2}$ culture Falcon flask ${ }^{9}$. MSCs identification was done by FACS analysis using CYTOMICS FC 500 (Beckman Coulter, FL, U.S.A.) and CXP software version 2.2 for interpretation, and morphologically by their fusiform shape. Undifferentiated BM-MSCs were labeled with $\mathrm{PKH} 26$ according to the manufacturer's recommendations (Sigma, Saint Louis, Missouri, USA) for in vivo tracing and observed in unstained liver tissues cryosections using fluorescence microscope (Leica Microsystems, CMS GmbH, ErnstLeitz-Strasse, Wetzlar D-35578, Germany).

\section{Experimental animals}

After obtaining an approval from Institutional Animal Care, 32 female 6 weeks white albino rats were obtained and cared in the animal house unit. Sample size was calculated using $\mathrm{G}$ power software according to the primary outcome (improvement of liver functions) and based on Tao et al., 2017 [7], with power 80\% and $\alpha$ probability error 0.05 . Liver fibrosis was induced by injection of $0.2 \mathrm{ml} / 100 \mathrm{~g}$ body weight of $40 \mathrm{ml} / \mathrm{l}$ carbon tetrachloride (CCl4) (Sigma, St. Louis, USA) dissolved in equal volume of castor oil (Sigma, St. Louis, USA) subcutaneously. The injection was given twice a week for 6 weeks [7].

Liver fibrosis was confirmed by histopathological examination of two randomly selected rats, Animals were randomly divided into three groups (10 animals each): Group 1: A negative control; Group 2: Induced liver fibrosis (pathological control); and Group 3: Induced liver fibrosis that received undifferentiated BM MSCs (3 $\times 10^{6}$ cells $/ \mathrm{ml}$ intraperitoneally/single dose) [8]. After 4 weeks of stem cell administration, venous blood was collected from the retro-orbital vein then all rats were killed by cervical dislocation then sacrificed; liver tissues were harvested and subjected to histological and molecular study.

\section{Histological study}

Liver samples were collected and fixed in $10 \%$ buffered formalin for $24 \mathrm{~h}$. Serial $5 \mu \mathrm{m}$ paraffin sections were prepared and stained with hematoxylin and eosin ( $\mathrm{H}$ and $\mathrm{E}$ ) for histological structure analysis and Masson trichrome (MT) for fibrous tissue study.

\section{Histochemical study}

Periodic acid-Schiff (PAS) reaction with hematoxylin counterstain was used to detect the presence of glycoprotein at the basement membrane. Immune histochemical study using alpha smooth muscle actin ( $\alpha-S M A)$ to detect the activity of myoepithelial cells (MECs) and BCL2 to detect cell apoptosis [9].

\section{Immunohistochemical $\alpha-S M A$ study}

The prepared deparaffinized sections were blocked with $1.5 \%$ normal goat serum in PBS and then were incubated at room temperature for $45 \mathrm{~min}$ with $6 \mathrm{ml}$ pre-diluted monoclonal anti- $\alpha$-SMA) primary (1ry) mouse antibody (Ab (ab5694) (Dako Corporation, Glostrup, Denmark). The sections were then incubated with a second-stage biotinylated antibody (biotinconjugated goat anti-rabbit IgG, 1:200, $1 \mathrm{~h}$, at room temperature). The reaction products were visualized; after rinsing in PBS, by immersing the section into the chromogen diaminobenzidine. Finally, the sections were counterstained with Mayer's hematoxylin, dehydrated, and mounted. The positive tissue control showed brown cytoplasmic reaction. The negative control was processed in the same way, but omitting the step of 1ry $A b$.

\section{Immunohistochemical BCL2 study}

Using the streptavidin immunoperoxidase method, the deparaffinized sections were rehydrated and processed. For about $10 \mathrm{~min}$, sections were submitted to antigen retrieval by microwave oven treatment in $0.01 \mathrm{~mol} / \mathrm{L}$ citrate buffer $(\mathrm{pH} \mathrm{6.0)}$. Then, slides were incubated in $10 \%$ normal serum for 30 min followed by an overnight incubation at $4 \mathrm{f}$ with the appropriately diluted primary $\mathrm{Bcl}-2$ antibody (Beyotime Inc., China) which were used at 1:100 dilution. Then, samples were incubated for $15 \mathrm{~min}$ at $37^{\circ} \mathrm{C}$ with biotinylated 
anti-rabbit immunoglobulins followed by incubation with streptavidin peroxidase complexes for $15 \mathrm{~min}$ at $37^{\circ} \mathrm{C}$. After rinsing in PBS, the reaction products were visualized by immersing the section into the chromogen diaminobenzidine. At the end, the sections were counterstained with Mayer's hematoxylin, dehydrated, and mounted. The negative control was processed in the same way, but omitting the step of 1ry Ab.

\section{Morphometric measurements}

1. Mean area \% of collagen fibers was measured using ImageJ ${ }^{\circledR}$ software (National Institutes of Health, Bethesda, USA). The measurements were done at $\times 400$ in six fields of the liver sections stained by Masson's trichrome in five animals from each group

2. Mean area \% of $\alpha-S M A$ expression was estimated in positive cells using ImageJ ( ) software (National Institutes of Health, Bethesda, USA). The measurements were done at $\times 400$ in six fields of the liver $\alpha$-SMA immunostained sections in five animals from each group

3. The number of BCL2-positive nuclei of the liver cells was counted in 10 randomly selected different microscopic fields for each specimen at a magnification power of $\times 400$.

\section{Colorimetric assay}

ALT and albumin levels were assessed in serum (Spectrum, Hannover, Germany), according to manufacturer's instructions.

\section{Quantitative RT-PCR for studied genes}

The liver tissues from all studied groups were lysed and total RNA was isolated with Gene JET Kit (Thermo Fisher Scientific Inc., Germany, \#K0732). For reverse transcription, about $5 \mu \mathrm{l}$ from the total RNA from each sample were used with subsequent amplification with Bioline, Meridian Life Science Company, U.K. (SensiFAST $^{\text {TM }}$ SYBR R Hi-ROX) one-step kit (catalog number $\mathrm{PI}-50217 \mathrm{~V}$ ) in a 48-well plate using the stepone instrument (Applied Biosystems, U.S.A.). Thermal profile was as follows: $45^{\circ} \mathrm{C}$ for $15 \mathrm{~min}$ in one cycle (for cDNA synthesis), $10 \mathrm{~min}$ at $95^{\circ} \mathrm{C}$ for reverse transcriptase enzyme inactivation, followed by 40 cycles of PCR amplification. Each cycle was continued for $10 \mathrm{~s}$ at $95^{\circ} \mathrm{C}, 30 \mathrm{~s}$ at $60^{\circ} \mathrm{C}$, and $30 \mathrm{~s}$ at $72^{\circ} \mathrm{C}$. The expression of studied genes gene was normalized relative to the mean critical threshold (CT) values of GAPDH as the housekeeping gene by the Ct method. Primers' sequences for studied genes are listed in Table 1.
Table 1: Primers sequence for studied genes

\begin{tabular}{ll}
\hline Gene & Primer sequence from $5^{\prime}-3^{\prime}$ \\
\hline TGF- $\beta$ & Forward: CTACTGCTTCAGCTCCACAG \\
& Reverse: GCACTTGCAGGAGCGCAC \\
TNF- $\alpha$ & Forward: GCCTCTTCTCATTCCTGCTT \\
& Reverse: CACTTGGTGGTTTGCTACGA \\
VEGF & Forward: CTCCGAACCATGAACTTTCTGCTC \\
& Reverse: CAGCCTGGCTCACCGCCTTGGCTT \\
IL6 & Forward: TTCCATCCAGTTGCCTTCTT \\
& Reverse: ATTTCCACGATTTCCCAGAG \\
GAPDH & Forward: ACAGTCCATGCCATCACTGCC \\
& Reverse: GCCTGCTTCACCACCTTCTTG \\
\hline
\end{tabular}

\section{Statistical method}

Data were analyzed using SPSS computer software version 22. Data were expressed as mean \pm SD. Comparison between groups was done using ANOVA and post hoc tests for multiple comparisons. Correlation between quantitative variable was done using Pearson's correlation. All tests are two tailed. Results were considered significant at $p<0.05$

\section{Results}

The morphological identification of MSCs revealed fusiform fibroblast like cells (Figure 1a), MSCs were then characterized by assessment of cell surface phenotyping. The cells showed positive staining against MSC markers CD29 (Figure 1b) and CD90 (Figure 1c) but negative against CD34 (Figure 1d), this indicated that the enrichment of the cells was good for rat MSCs. MSCs were labeled in culture with $\mathrm{PKH}$ (Figure 1e). PKH-labeled MSCs were traced in liver tissue (Figure 1f).

\section{PCR results}

The inflammatory cytokines IL-6 and TNF show significant increase in their expression in CCL4 group compared to the normal control group $(p<0.001$ and 0.002 ), respectively, while no significant difference between the MSCs treated group and control group ( $p=0.49$ and 0.09 ), respectively. Significant decrease in their expression in MSCs treated group compared to CCL4 group ( $p<0.001$ and 0.028 ), respectively (Figure 2a and b).

Significant decrease in vascular endothelial growth factor (VEGF) gene expression in CCL4 group compared to the normal control group ( $p=0.004)$, while no significant difference between the MSCs treated group and control group ( $p=0.2$ ). Significant increase in its expression in MSCs treated group compared to CCL4 group ( $p=0.035$ ) (Figure $2 c)$.

The TGFß gene expression was significantly higher in CCL4 and MSCs treated groups compared 

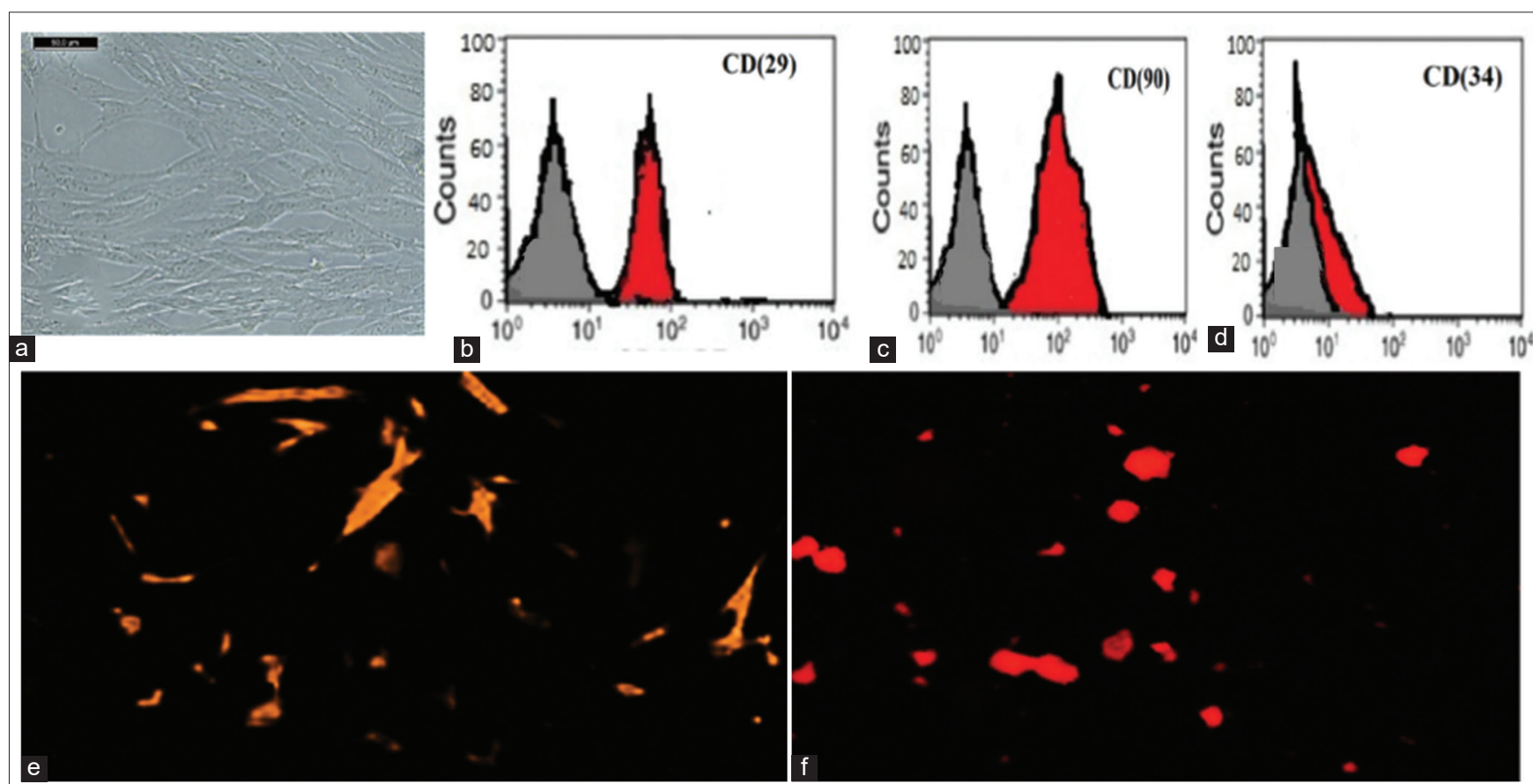

Figure 1: Mesenchymal stem cells (MSCs) were assessed for propagation, characterization, and labeling. (a) MSCs were isolated as fibroblastlike cells. (b) FACS analysis characterized MSCs; they were positive for photographs of flow cytometer analysis of the cell surface to verify the surface marker expressions. CD29 positive. (c) CD90 positive. (d) CD34 negative. (e) MSCs were labeled with GFP in vitro. (f) Uterine tissue showed in vivo GFP-labeled cells for tracing of MSCs in uterine tissue

to the normal control group ( $p<0.001$ and 0.046 ). Significant decrease in its expression in MSCs treated group compared to CCL4 group $(p<0.001)$ (Figure 2d).

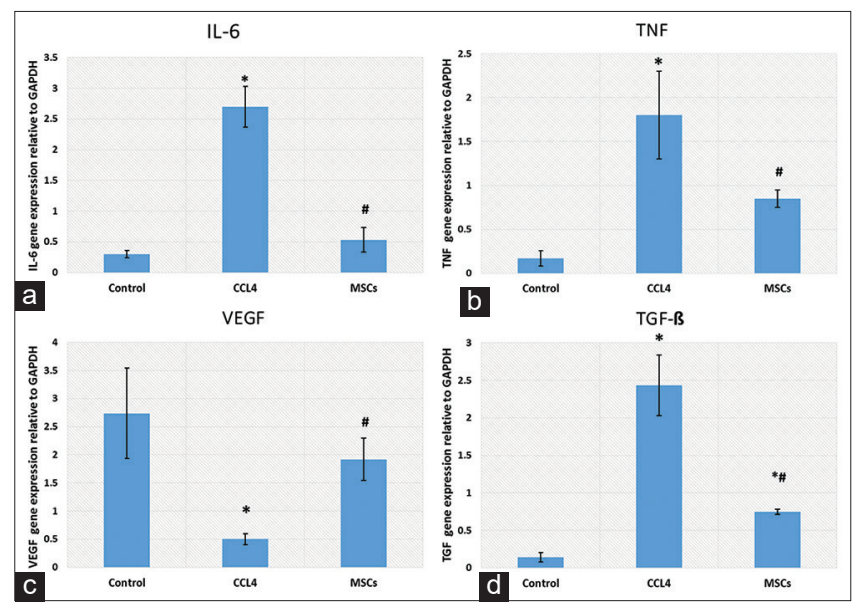

Figure 2: (a-d) PCR results of IL-6, TNF, VEGF, and transforming growth factor (TGF). Data were expressed as mean $\pm S D$. $p<0.05$ was considered statistically significant. ${ }^{*}$ Denotes significant difference versus control group. "Denotes significant difference versus control group. Significant increase in the expression of IL-6, TNF, and TGF in induced fibrosis group with decrease in their expression after mesenchymal stem cells treatment, the reverse result was observed with VEGF expression

Serum ALT was significantly higher in CCL4 and MSCs treated groups compared to the normal control group ( $p<0.001$ and 0.01$)$. Significant decrease in its level in MSCs treated group compared to CCL4 group $(p<0.001)$ (Figure 3a).
Serum albumin was significantly decreased in CCL4 group compared to the normal control group $(p<0.001)$ while no significant difference between the MSCs treated group and control group $(p=0.11)$. Significant increase in its level in MSCs treated group compared to CCL4 group ( $<$ 0.001) (Figure 3b).

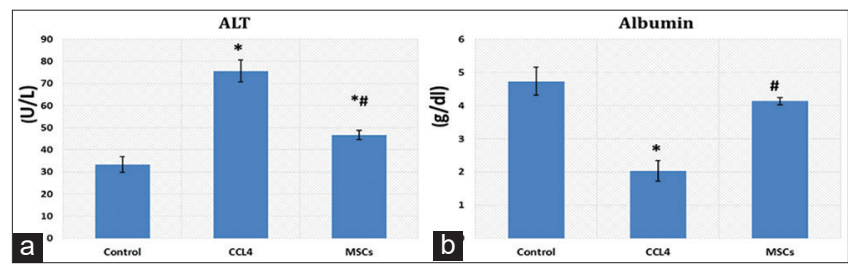

Figure 3: ( $a$ and b) Serum albumin and ALT. Data were expressed as mean $\pm S D . p<0.05$ was considered statistically significant. ${ }^{*}$ Denotes significant difference versus control group. "Denotes significant difference versus control group. Significant increase in ALT and decrease in albumin in induced fibrosis group with improvement of liver function and serum albumin after mesenchymal stem cells treatment

\section{Histological results}

Examination of $\mathrm{H}$ and $\mathrm{E}$ liver-stained sections of the control group revealed ill-defined hepatic lobules formed of branching and anastomosing cords of hepatocytes radiating from the central vein to the periphery of the lobule and was separated by blood sinusoids, which were lined by flat endothelial cells. The portal areas contained branches of bile duct lined with simple cubical epithelium, a branch of portal vein, 
which is the widest with a thin wall, and a branch of hepatic artery that is rounded with narrow lumen. The hepatocytes appeared as polygonal cells having acidophilic cytoplasm and central rounded vesicular nuclei with prominent nucleoli. Some cells were binucleated (Figure 4a-c).

In (CCL4 alone group), revealed that, marked thickening of the interlobular septa forming nodular structure at some areas with inflammatory cellular infiltration and marked dilatation and congestion of central vein, the portal veins and blood sinusoids. Furthermore, disorganization of the lobular architecture could be detected. Most of the hepatocytes contained multiple, large cytoplasmic vacuoles and some hepatocytes had deeply acidophilic cytoplasm and deeply stained nuclei (Figure 4d-f). After MSCs administration, remarkable improvement in the hepatocytes was noticed as they appeared nearly similar to that of the control rats. Only few hepatocytes appeared with slight vacuolated cytoplasm (Figure $4 \mathrm{~g}$ and $\mathrm{h}$ ).

In Masson's trichrome stained sections, the parenchyma of the liver in control groups appeared to be supported with a stroma of very delicate meshwork of collagenous fibers. Few collagenous fibers surrounding the central veins, in portal area and in capsules, were seen (Figure $5 \mathrm{~A} 1$ and $\mathrm{A} 2$ ).

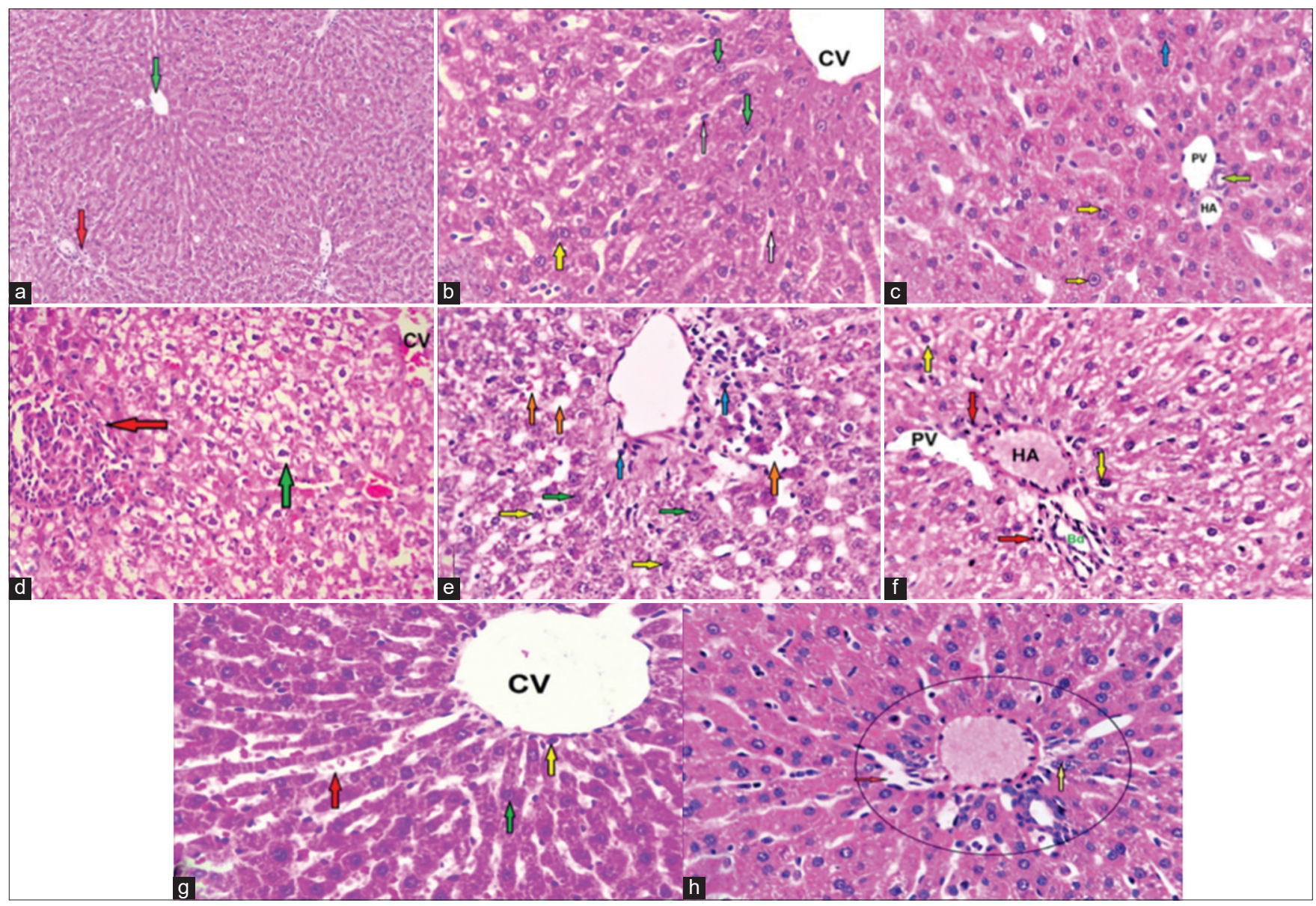

Figure 4: Photomicrographs of the liver sections of rats of all groups stained with H\&E: (a) Control group showing normal hepatic loblar architecture, radiating cords of hepatocytes from the central vein (green arrow) at the center of classic hepatic lobule and portal area (red arrow) (x 100). (b): Control group showing central ven (CV) with its normal lining endothelium and blood sinusoid (white arrows) in between cords of hepatocytes which showing large rounded vesicular nuclei (green arrows) and acidophilic cytoplasm. Some of the cells appear bi-nucleated (yellow arrow). (x400). (c) Control group showing portal area has a branch of bile duct (green arrow) lined with simple cubical epithelium, a branch of the portal vein (PV) having a thin wall and wide lumen and branch of the hepatic artery (HA). The hepatocytes have vesicular nuclei with prominent nucleoli (yellow arrows); some are bi-nucleated (blue arrow). (x400). (d): CCL4 alone group showing loss of normal hepatic architecture, marked fibrous septa with complete nodules formation (red arrow) and dilated congested central vein (cv). Also, many of the hepatocytes contain cytoplasmic vacuoles ( green arrow) (×100). (e): CCL4 alone group showing many of hepatocytes contain cytoplasmic vacuoles ( white arrow), dilated central vein and blood sinusoids (red arrows). Some of the nuclei of hepatocytes showing dysplastic changes in the form of deeply stained nuclei and pleomorphism (yellow arrows) but other hepatocytes still have a visculer nuclei (green arrows). Cellular infiltration (blue arrows) around central vein can be observed. $(\times 400)(f)$ : CCL4 alone group showing portal area with marked dilatation of the portal veins (PV), congested hepatic artery (HA). Some hepatocytes appear vacuolated and have dense nuclei (yellow arrows). There are a heavy inflammatory cellular infiltrations (red arrow) in portal area can be detected (×400). (g): CCL4/ BM-MSCs group. The hepatocytes have acidophilic cytoplasm and central, rounded vesicular nuclei (green arrow) nearly as a control group but slightly dilated central vein (CV) can be observed, few of cellular infiltration around central vein (yellow arrow)and slightly dilated congested blood sinusoids (red arrow) (×400). (h): CCL4/ BM-MSCs group. Portal area (circled) have a mild dilation of blood sinusoids (red arrow) and decrease in cellular infiltration (yellow arrow) (×400). 


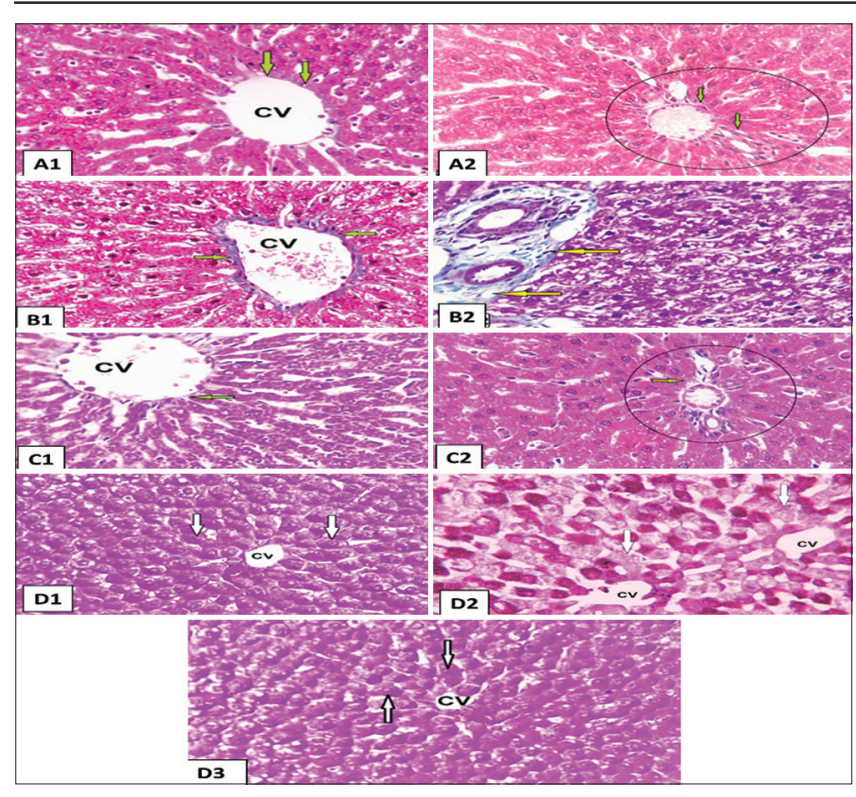

Figure 5: Photomicrographs of rat liver tissue stained with Masson trichrome of all groups $(\times 400)$. (A1) Control group showing few collagen fibers (arrows) surrounding the central vein $(C V),(P)$, and in the capsule (C) in control group. (A2) Control group in portal area showing few collagen fibers (circled). Portal area. (B) Carbon tetrachloride (CCL4) alone group showing numerous collagen fibers (arrows) surrounding portal area. (C1) CCL4/BM- mesenchymal stem cells (MSCs) group showing very few collagen fibers surrounding the CV more or less as a control group. (C2) CCL4/BM-MSCs group showing few collagen fibers (arrow) surrounding portal area (circled) more or less as a control group. The photomicrographs of rat liver tissue with PAS reaction in all groups $(\times 400)$. (D1) Control group showing strong positive reaction for PAS in the cytoplasm of the hepatocytes in the form of dark purple granules, especially in the cells around the CV (arrows). (D2) CCL4 group showing mild decrease in the intensity of the positive reaction for PAS in the cytoplasm of the hepatocytes (arrows). (D3) CCL4/ BM-MSCs group showing strong positive reaction for PAS in the cytoplasm of the hepatocytes around the $\mathrm{CV}$ and moderate positive reaction in those peripheral within the hepatic lobules (arrows)

In CCL4 alone group, the stroma was well defined. There was thick connective tissue capsule and an apparent increase in the collagen fibers around the central veins, in between hepatocyte cords and in portal areas (Figure 5B). In CCL4/MSCs group, few collagen fibers were detected (Figure 5C1 and 5C2).

In PAS reaction, control group and CCL4/ BM-MSCs group showed that strong positive reaction means preservation of the glycogen contents was seen in the cytoplasm of the hepatocytes throughout the different zones of the hepatic lobules in the form of dark purple granules, especially in the cells around the central vein (Figure 5D1 and 5D3). However, CCL4 group showed marked depletion of PAS +ve glycogen granules in most of hepatic lobules sparing a small area around the central vein where liver cells were mildly affected (Figure 5D2).

Immune stained sections for $\alpha$-SMA showed few mildly immune reacted $\alpha$-SMA-positive cells, in between the hepatocytes and around the central veins in the control groups (Figure 6A1). On the other hand, in CCL4 alone group, numerous strong immune reacted $\alpha$-SMA-positive cells were detected in-between the hepatocytes, around the central veins as well as in the connective tissue septa between the hepatic lobules (Figure 6A2). These cells showed intense positive brownish cytoplasmic reaction. They appeared as small spindle-shaped cell bodies with multiple cytoplasmic processes. These $\alpha$-SMA-positive cells were apparently few in CCL4/MSCs group (Figure 6A3).

Immune stained sections for BCL2 showed that very few hepatocytes had a positive nuclear reaction in the control group (Figure 6B1) and in CCL4/MSCs group (Figure 6B2) than that in CCL4 alone group (Figure 6B3).

\section{Morphometric results}

The area percentage of both collagen and $\alpha$-SMA showed a significant increase $(p<0.001)$ in CCL4 alone group as compared to the other groups. Non-significantly difference was noticed between the control and CCL4/MSCs groups. The mean number of BCL2-positive cells/HPFs was significantly high $(p<0.001)$ in the CCL4 alone group as compared to other groups (Table 2).

Table 2: Area percentage of collagen, a smooth muscle actin, and mean number of BCL2-positive cells

\begin{tabular}{lcll}
\hline & Control group & CCL4 alone group & $\begin{array}{l}\text { CCL4/BM- mesenchymal } \\
\text { stem cells group }\end{array}$ \\
\hline $\begin{array}{l}\text { Area percentage of } \\
\text { collagen fibers (\%) }\end{array}$ & $11.8 \pm 1.9$ & $59.7 \pm 4.12\left(^{*}\right)$ & $13.5 \pm 2.7^{\#}$ \\
$\begin{array}{l}\text { Area percentage of } \alpha \\
\text { smooth muscle actins } \\
(\%) \text { Number of BCL2/ }\end{array}$ & $12.58 \pm 2.33$ & $48.92 \pm 3.2^{*}$ & $14.7 \pm 2.8^{\#}$ \\
$\begin{array}{l}\text { HPFs } \\
\text { Hata were expressed as mean } \pm \mathrm{SD} ; \mathrm{p}<0.05 \text { was considered statistically significant. }{ }^{*} \text { Denotes significant } \\
\text { difference versus control group. }{ }^{*} \text { Denotes significant difference versus control group. CCL4: Carbon } \\
\text { tetrachloride. Table 2 shows changes in area percentage of collagen, a smooth muscle actin, and mean } \\
\text { number of BCL2-positive cells/high-power field in different groups }\end{array}$
\end{tabular}

\section{Discussion}

Liver fibrosis is the endpoint of chronic inflammatory diseases. It is developed because of an abnormal accumulation of extracellular matrix components. Hepatic fibrosis finally leads to liver failure; despite being slowly progressive [4].

MSCs are a promising therapeutic agent for cellbased tissue engineering and regenerative medicine. It has been reported that MSC transplantation is safe and widely tested in many clinical trials of neurological, cardiovascular, and immunological diseases with promising results [10].

BM-MSCs are capable of homing to damaged tissues, then differentiate and stimulate a local repair response [11]. Hence, this study was performed to investigate if the BM-MSCs could 


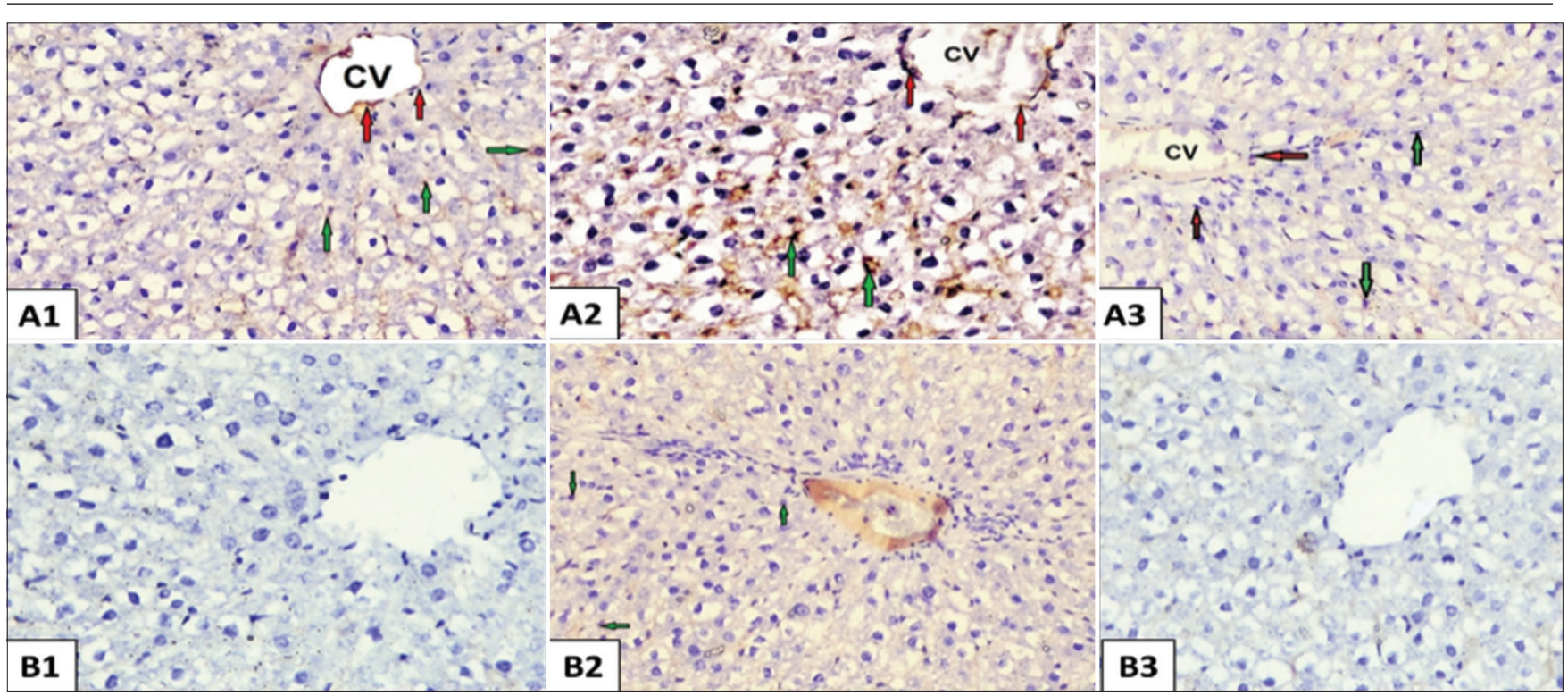

Figure 6: Photomicrographs of rat liver tissue with a-SMA immune reaction in all groups (×400): (A1): From the control group showing few a-SMA-positive cells (red arrow) around the central vein (CV) and in between the hepatocyte (green arrows). (A2) From carbon tetrachloride (CCL4) alone group showing an apparent increase in a-SMA-positive cells (red arrows) around CV, and in between the hepatocyte. Inset: a-SMA-positive cells appear spindle in shape with cytoplasmic processes. (A3) From CCL4/BM-mesenchymal stem cells (MSCs) showing few $\alpha$-SMA-positive cells around the portal tracts and in between the hepatocytes (red arrow) more or less similar as control group. The photomicrographs of rat liver tissue with of BCL2 immune reaction (×400): (B1) From the control group showing very few of hepatocytes are positive nuclei of BCL2 reaction. (B2): From CCL4 alone group showing BCL2-positive nuclei of some of hepatocytes (green arrows). (B3) From CCL4/BM-MSCs group showing very few of hepatocytes are positive nuclei BCL2 reaction

restore the liver structure in the experimental model of liver fibrosis. CCL4 was used in this study to induce liver fibrosis because among the different experimental animal models of liver fibrosis, the CCL4 model was the most closely resembling that of human liver cirrhosis [12]. Four weeks after CCL4 administration, light microscopic examination of the liver revealed loss of the usual hepatic architecture, many vacuoles with dark stained nuclei in most of the liver cells. Liver fibrosis was clearly evidenced, in the present work, by a significant increase in area percentage of the collagen fibers in MT stained section. The expression of $\alpha$-SMA was determined as a marker for the activity of HSCs, which were identified as the primary cell type that mediates fibrogenesis [13]. Hence, immune staining of $\alpha-S M A$ was done to detect the activity of HSCs. There was a significant increase in the area percentage of $\alpha$-SMA-positive cells in CCL4 alone group as compared to that of control group. This increase in the area percentage of $\alpha$-SMA reflected an increase in the activity of HSCs. HSCs are quiescent nonparenchymal cells that function as storage site for Vitamin A in normal liver. In pathological conditions like liver fibrosis, HSCs lose these storage functions and changes from the star-shaped stellate like cells to myofibroblasts like cell. These newly transformed cells can synthesize a large amount of component of ECM such as proteoglycan, collagen, and adhesive glycoproteins [14]; thus, $\alpha$-SMA is considered a good marker for the detecting myofibroblasts like cells [15], it was explained that hepatic fibrosis is stimulated by hepatocytes damage leading to activation of Kupffer cells and subsequently release of cytokines and growth factors. These factors could activate HSCs which proliferate and transformed into myofibroblasts like cells that deposit large amounts of connective tissue components [16]. Moreover, CCL4 causes oxidative stress that activates HSCs [17]. In rats with CCL4-induced liver fibrosis were treated with BM-MSCs (CCL4/MSCs group), the light microscopic picture of the hepatocytes and also the liver function was nearly similar to that of the CCL4 alone group. Moreover, there was a progressive increase in the liver fibrosis. The area percentage of collagen fibers and $\alpha$-SMA-positive cells was significantly increased as compared to that of CCL4 alone group. Intraperitoneal route was chosen for BM-MSCs injection in experimental fibrotic rats. The peritoneal cavity can be considered as a favorable site for cell transplantation, due to large volume of cells can be implanted, technically easy to perform, less invasive, and less liable to induce trauma [18].

Light microscopic examination of CCL4/ MSCs group revealed an improvement of the liver structure. Most of hepatocytes appeared nearly as those of the control group and regained their function. BM-MSCs differentiated into hepatic oval cells and then to hepatocyte-like cells. The damaged hepatocytes were repaired, and fibrosis was resolved, resulting in an overall improvement in liver function [19]. The area percentage of the collagen fibers and area percentage of $\alpha$-SMA-positive cells were significantly decreased as compared to CCL4 alone group. BM-MSCs improved liver fibrosis by down regulating the profibrotic genes 
and upregulating antifibrotic hepatic genes [20]. Moreover, it was reported that MSCs could inhibit process of HSCs transition from the quiescent state to activated state and induce HSCs apoptosis through release of interleukin-10 [21]. Recently, it was found that BM-MSCs reduced expression of collagen type I and $\alpha$ - SMA [22]. In this study we showed marked depletion in the amount of glycogen in hepatocytes more detected in peripheral zone in liver of rats treated with CCL4 alone group this in agreement with previous study which proved that toxins may lead to depletion of glycogen stores in the liver [23].

In the present study, BCL2 showed weak BCL2 reaction in liver of control group and CCL4/ BM-MSCs group indicating strong antiapoptotic effect of BM-MSCs to help needed regeneration after injury. Interestingly, $\mathrm{BCl} 2$ has an anti-apoptotic effect. This in agreed with author report that $\mathrm{Bcl} 2$ exerts antiapoptotic effects through antioxidant activity or inhibition of ROS generation [24].

$\mathrm{IL}-6$ is a cytokine that regulates the synthesis of acute-phase proteins in the liver and is involved in the pathogenesis of liver fibrosis [25]. In this study, we found significant elevation of inflammatory cytokines IL-6, TNF, and fibrotic gene TGF in CCL4-induced fibrosis rats and decrease in its expression after MSCs treatment, together with an improvement of hepatic function and elevation of serum albumen and VEGF gene after MSCs treatment. This agreed with the previous study reported that IL-6 plays a key role in hepatic fibrosis and it stimulates the synthesis of collagen fibers within hepatocytes [25]. Another study reported significant elevation of IL- 6 and IL- 1 in chronic liver diseases patients [26]. This augmented by more study that revealed evaluated serum cytokine levels (IL-6 and TNF- $\alpha$ ) in chronic hepatic patients [27]. In a clinical trial to investigate the effect of human umbilical cord MSCs on the immune function and prognosis of patients with decompensated hepatitis B cirrhosis, it was found that transplantation of UCMSCs can inhibit the proliferation of T-cells and B-cells and the differentiation of T8 cells and reduce the production of inflammatory cytokines IL-6, TNF $\alpha$, and TGF. Thus, it can attenuate liver inflammatory response and liver cell damage and reduce the probability of hepatic failure [28]. Another study demonstrates that BM-MSCMVs have anti-fibrotic, anti-inflammatory, and proangiogenic properties which can reveal $\mathrm{CCL}_{4}$-induced liver fibrosis in rats; this approved as BM-MSC-MVs treated rats showed significant increase in serum albumin levels and VEGF and significant decrease in serum ALT and TGF- $\beta$, collagen- $1 \alpha$, and IL-1 $\beta$ compared to $\mathrm{CCL}_{4}$ fibrotic group [29]. Further study reported that BM-MSCs induced positive changes in serum bilirubin and albumin and downregulated expression TGF and procollagen- $\alpha 1$ compared CCL4induced fibrosis rats [30].

\section{Conclusion}

From the previously discussed results, it was concluded that BM-MSCs markedly decreased the induced liver fibrosis by CCL4 in albino rats. Hence, stem cell therapy offers a hope to patient waiting for liver transplantation. Further studies on the differentiation of MSCs into hepatocytes in vitro and their use in treatment of liver fibrosis were recommended.

\section{References}

1. Weiskirchen R, Weiskirchen S, Tacke F. Recent advances in understanding liver fibrosis: Bridging basic science and individualized treatment concepts. F1000Res. 2018;7:921. https://doi.org/10.12688/f1000research.14841.1

PMid:30002817

2. Trautwein C, Friedman SL, Schuppan D, Pinzani M. Hepatic fibrosis: Concept to treatment. J Hepatol. 2015;62(1):S15-24. https://doi.org/10.1016/j.jhep.2015.02.039

PMid:25920084

3. Eom YW, Shim KY, Baik SK. Mesenchymal stem cell therapy for liver fibrosis. Korean J Intern Med. 2015;30(5):580-9. https://doi. org/10.3904/kjim.2015.30.5.580

PMid:26354051

4. Usunier B, Benderitter M, Tamarat R, Chapel A. Management of fibrosis: The mesenchymal stromal cells breakthrough. Stem Cells Int. 2014;2014:340257. https://doi.org/10.1155/2014/340257

PMid:25132856

5. Parekkadan B, van Poll D, Megeed Z, Kobayashi N, Tilles AW Berthiaume F, et al. Immunomodulation of activated hepatic stellate cells by mesenchymal stem cells. Biochem Biophys Res Commun. 2007;363:247-52. https://doi.org/10.1016/j. bbrc.2007.05.150

PMid:17869217

6. Chen S, Xu L, Lin N, Pan W, Hu K, Xu R. Activation of Notch1 signaling by marrow-derived mesenchymal stem cells through cell-cell contact inhibits proliferation of hepatic stellate cells. Life Sci. 2011;89(25-26):975-81. https://doi.org/10.1016/j. Ifs.2011.10.012

PMid:22056375

7. Wu T, Li J, Li Y, Song H. Antioxidant and hepatoprotective effect of swertiamarin on carbon tetrachloride-induced hepatotoxicity via the Nrf2/HO-1 pathway. Cell Physiol Biochem. 2017;41(6):2242-54. https://doi.org/10.1159/000475639 PMid:28448964

8. Farouk S, Sabet S, Abu Zahra FA, El-Ghor AA. Bone marrow derived-mesenchymal stem cells downregulate IL17A dependent IL6/STAT3 signaling pathway in CCl4-induced rat liver fibrosis. PLoS One. 2018;13(10):e0206130. https://doi. org/10.1371/journal.pone.0206130 PMid:30346985

9. Suvarna SK, Layton C, Bancroft JD, editors. Bancroft's Theory and Practice of Histological Techniques. $7^{\text {th }}$ ed. Philadelphia, PA: Churchill Livingstone; 2013. https://doi.org/10.1016/ b978-0-7020-6864-5.05001-5

10. Gebler A, Zabel O, Seliger B. The immunomodulatory capacity of 
mesenchymal stem cells. Trends Mol Med. 2012;18(2):128-34 https://doi.org/10.1016/j.molmed.2011.10.004 PMid:22118960

11. $\mathrm{Fu} \mathrm{X}, \mathrm{Li} \mathrm{H}$. Mesenchymal stem cells and skin wound repair and regeneration: Possibilities and questions. Cell Tissue Res. 2009;335(2):317-21. https://doi.org/10.1007/ s00441-008-0724-3

PMid:19034523

12. Geerts $A M$, Vanheule $E$, Praet $M$, Van Vlierberghe $H$, De Vos M, Colle I. Comparison of three research models of portal hypertension in mice: Macroscopic, histological and portal pressure evaluation. Int J Exp Pathol. 2008;89(4):251-63. https://doi.org/10.1111/j.1365-2613.2008.00597.x PMid: 18715470

13. Cheung PY, Zhang Q, Zhang YO, Bai GR, Lin MC, Chan B, et al. Effect of WeiJia on carbon tetrachloride induced chronic liver injury. World J Gastroenterol. 2006;12(12):1912-7. https:// doi.org/10.3748/wjg.v12.i12.1912 PMid:16609998

14. Senoo H, Yoshikawa K, Morii M, Miura M, Imai K, Mezaki Y. Hepatic stellate cell (Vitamin A-storing cell) and its relative-past, present and future. Cell Biol Int. 2010;34(12):1247-72. https://doi.org/10.1042/cbi20100321

PMid:21067523

15. Jung YJ, Ryu KH, Cho SJ, Woo SY, Seoh JY, Chun CH, et al. Syngenic bone marrow cells restore hepatic function in carbon tetrachloride-induced mouse liver injury. Stem Cells Dev. 2006;15(5):687-95. https://doi.org/10.1089/scd.2006.15.687 PMid:17105404

16. Bauer M, Schuppan D. TGFbeta1 in liver fibrosis: Time to change paradigms? FEBS Lett. 2001;502:1-3. PMid:11478937

17. Yang FR, Fang BW, Lou JS. Effects of Haobie Yangyin Ruanjian decoction on hepatic fibrosis induced by carbon tetrachloride in rats. World J Gastroenterol. 2010;16(12):1458-64. https://doi. org/10.3748/wjg.v16.i12.1458 PMid:20333785

18. $X u Y Q$, Liu ZC. Therapeutic potential of adult bone marrow stem cells in liver disease and delivery approaches. Stem Cell Rev. 2008;4(2):101-12. https://doi.org/10.1007/s12015-008-9019-z PMid:18481229

19. Oyagi S, Hirose $M$, Kojima M, Okuyama M, Kawase $M$, Nakamura $\mathrm{T}$, et al. Therapeutic effect of transplanting HGFtreated bone marrow mesenchymal cells into CCl4-injured rats. J Hepatol. 2006;44(4):742-8. https://doi.org/10.1016/j. jhep.2005.10.026 PMid: 16469408

20. Ali G, Masoud MS. Bone marrow cells ameliorate liver fibrosis and express albumin after transplantation in CCl4-induced fibrotic iver. Saudi J Gastroenterol. 2012;18(4):263-7. https:// doi.org/10.4103/1319-3767.98433

\section{PMid:22824770}

21. Dai LJ, Li HY, Guan LX, Ritchie G, Zhou JX. The therapeutic potential of bone marrow-derived mesenchymal stem cells on hepatic cirrhosis. Stem Cell Res. 2009;2(1):16-25. https://doi. org/10.1016/j.scr.2008.07.005

PMid:19383405

22. Shao $\mathrm{CH}$, Chen SL, Dong TF, Chai H, Yu Y, Deng L, et al. Transplantation of bone marrow-derived mesenchymal stem cells after regional hepatic irradiation ameliorates thioacetamideinduced liver fibrosis in rats. J Surg Res. 2014;186(1):408-16. https://doi.org/10.1016/j.jss.2013.08.016

PMid:24071025

23. Zhonghua G, Zang B, Zazhi W, Chen $J$ and liu J. Ultrastructure study of hepatocellular carcinoma treated by diammunedichloroplatinum Jie-Bo. Liyuan. 2000;8(2):89-90.

24. Youle RJ, Strasser A. The BCL-2 protein family: Opposing activities that mediate cell death. Nat Rev Mol Cell Biol. 2008;9(1):47-59. https://doi.org/10.1038/nrm2308 PMid:18097445

25. Choi I, Kang HS, Yang Y, Pyun KH. IL-6 induces hepatic inflammation and collagen synthesis in vivo. Clin Exp Immunol. 1994;95(3):530-5. https://doi.org/10.1111/j.1365-2249.1994. tb07031.x PMid:8137551

26. Prystupa A, Kiciński P, Sak J, Boguszewska-Czubara A, ToruńJurkowska A, Załuska W. Proinflammatory cytokines (IL-1 $\alpha$, IL-6) and hepatocyte growth factor in patients with alcoholic liver cirrhosis. Gastroenterol Res Pract. 2015;2015:532615. https:// doi.org/10.1155/2015/532615

\section{PMid:26448742}

27. Mourtzikoua A, Alepakia M, Stamoulic M, Pouliakisa A, Sklirisc A, Karakitsos P. Effect of umbilical cord mesenchymal stem cell transplantation on immune function and prognosis of patients with decompensated hepatitis B cirrhosis. Inmunologia. 2014;33(1):41-50.

28. Fang $X Q$, Zhang JF, Song HY, Chen ZL, Dong J, Chen X, et al. Effect of umbilical cord mesenchymal stem cell transplantation on immune function and prognosis of patients with decompensated hepatitis B cirrhosis. Zhonghua Gan Zang Bing Za Zhi. 2016;24(12):907-10. https://doi.org/10.1111/jgh.14081 PMid:28073411

29. Sabry D, Mohamed A, Monir M, Ibrahim HA. The effect of mesenchymal stem cells derived microvesicles on the treatment of experimental CCL4 induced liver fibrosis in rats. Int J Stem Cells. 2019;12(3):400-9. https://doi.org/10.15283/ijsc18143 PMid:31474025

30. Truong $\mathrm{NH}$, Nguyen $\mathrm{NH}$, Van Le $\mathrm{T}, \mathrm{Vu}$ NB, Huynh $\mathrm{N}$, Van Nguyen $\mathrm{T}$, et al. Comparison of the treatment efficiency of bone marrow-derived mesenchymal stem cell transplantation via tail and portal veins in $\mathrm{CCl} 4$-induced mouse liver fibrosis. Stem Cells Int. 2016;2016:5720413. https://doi.org/10.1155/2016/5720413 